\title{
Comprehensive Analysis of the Wushu Education Performance and Multimedia Teaching in College
}

\author{
Wei Dongyi ${ }^{1}$, Lu Qingwu ${ }^{2}$, Liu Dan ${ }^{3}$, Fan Hongling ${ }^{4}$ and Long Xiaodong ${ }^{4 *}$ \\ ${ }^{1}$ Guangxi University of Chinese Medicine, Nanning, Guangxi, China \\ ${ }^{2}$ Chaoyang Middle School of Yongning District, Nanning, Guangxi, China \\ ${ }^{3}$ Affiliated Hospital of Jinggangshan University, Ji'an Jiangxi, China \\ ${ }^{4}$ P.E. Department, Jinggangshan University, Ji'an Jiangxi, China \\ *171761779@qq.com
}

\begin{abstract}
With computer-assisted instruction is widely used in university education, Multi-media teaching has produced a new form of education. Multimedia teaching has the effect of interactive and dynamic multi-dimensional, which enhances the students' learning interest and the understanding. In this paper, we make an empirical analysis about the impact of Wushu education on college students. The result shows that after using multimedia teaching, Wushu teaching can improve the physical function of college students, it will significantly improve the college students' sports view, sports value and sports motivation. At the same time, multimedia teaching can effectively improve the teaching quality. On this basis, we put forward relevant suggestions.
\end{abstract}

Keywords: Multimedia teaching, Wushu education, College students, Sports motivation

\section{Introduction}

Multimedia teaching is the inevitable trend of the traditional teaching method, and the teaching reform and development of colleges and universities. It is also an important factor to improve the quality of teaching. China has a long history of martial arts. It is a valuable Chinese cultural heritage[1]. Wushu Teaching in Colleges and universities is an important part of physical education, rich teaching content, is the source of students' learning interest, the long-term development of college martial arts teaching system, and it will promote students' physical and mental health development theory[2]. Further research on the influence of the martial arts teaching in Colleges and universities can promote the objective cognition and the scientific value of Wushu Teaching in Colleges and universities. Articles on College Students' physical function (FVC) and physical (50 meters, standing long jump, body anteflexion in sitting position) and tested on college students sports view, sport value, sport motivation and interest in sports, sports emotion, sports will of questionnaire survey, analysis of test data and index data and get results, colleges and universities to carry out teaching martial arts to provide certain reference and promotion.

Computer Assisted Instruction has promoted the reform and development of Chinese education, and has been widely used in the teaching of higher education in Colleges and universities[3]. It has made the traditional education in the educational idea, teaching mode, teaching content, and teaching methods and so on. However, many colleges and universities have some problems in the management of multimedia teaching quality. The main performance is that teachers have some misunderstandings in the teaching of multimedia. The quality of teachers is low. The quality assurance of multimedia teaching

${ }^{*}$ Corresponding Author 
in Colleges and universities is a systematic project. The teachers have the right to know and the teaching ability, the professional characteristics and the course construction.

Education Department, all kinds of schools and teachers are all of the development of the multimedia assisted teaching software has shown unprecedented enthusiasm. Multimedia teaching software is illustrated and lively, but also has the rich expressive force and strong interaction, as long as the use of multimedia courseware to teaching, teaching quality can greatly improve, and what is the fact? It is found that some teachers in higher learning institutions have had a wrong understanding of multimedia teaching. They think that a good class must be used, and the advanced multimedia method is a good class. At the same time, colleges and universities vigorously promote and develop multimedia teaching, but the lack of control of multimedia teaching management and teaching quality has become a common phenomenon, in the implementation of the negative effect, weaken, eliminate the advantages of multimedia, and even counterproductive.

\section{Literature Review}

\subsection{Multimedia Teaching in Colleges}

Multimedia teaching in the 1980s has begun to appear, but is then employed a variety of electronic media such as, slide projector, audio, video and other integrated in the classroom teaching[4]. This kind of teaching technology is also known as multimedia combination teaching or audio-visual teaching. In the ninety times, with the rapid development of computer technology, the multimedia computer has gradually replaced the comprehensive use of various teaching media[5-6]. Therefore, now we usually say that the multimedia teaching is refers to the use of multimedia computer and the use of multimedia teaching software in advance to carry out the teaching activity process, also known as Computer Assisted Instruction (CAI).

Multimedia teaching is the teaching process, according to the characteristics of teaching target and object, through the teaching design, reasonable choice and use of modern teaching media, the use of multimedia computer, integrated processing and control symbols, language, text, sound, graphics, images, video and other media information, the various elements of Multimedia teaching, and through the combination of sound and traditional teaching hand segment organic combination, to participate in the teaching process, to form a reasonable teaching process structure, to achieve the best teaching effect.

As a new discipline, the teaching method of multimedia teaching should not be completely used in the traditional teaching mode, but should have its own unique teaching method and teaching mode. The rapid development of information technology network has brought about a change to the teaching method and teaching mode of the whole education[7]. The growing popularity of network technology, especially the formation of multimedia technology, provides the material conditions for the modernization of teaching means. The idea of student centered teaching mode is a cognitive constructivism teaching theory based on the development of network technology in recent years. According to the theory of constructivism teaching, every learner is to construct the knowledge in his own unique way, based on his own experience. This teaching mode emphasizes the students' initiative, enthusiasm and participation in learning process. The teaching process should focus on the two aspects of "autonomous learning strategy" and "learning environment".

\subsection{Advantage of Multimedia Teaching}

Information technology has promoted the development of Chinese education in the last 20 years, and it is the inevitable trend of the reform and development of teaching reform 
and development, and also an important factor to improve the teaching quality[8]. Compared with the application of any advanced media, the introduction of multimedia technology makes the traditional education mode has a more profound reform, the quality of education and teaching efficiency have been improved significantly, and the key factor is that the multimedia information has a great promotion for education.

1) Enhance communication between teachers and students: multimedia technology rich and colorful teaching environment, innovative and lively teaching methods, mobilize the enthusiasm of students learning, and promote the exchange of students and teachers. From a certain extent, changed the traditional way of teaching, give students greater space for thinking; will simply memorize knowledge, knowledge representation of teaching mode conversion for the understanding of the teaching of thinking. In multimedia computer interactive learning environment, students can choose their own learning based on their own learning, learning interest, and can choose their own level of practice.

2) To meet the multidimensional thinking: the introduction of multimedia technology into the teaching process, so that students can really enter the visual, auditory and tactile senses and use the abstract logical thinking and concrete image thinking[9]. So as to participate in the learning process of multidimensional dynamic formula, breaking the difficulties and limitations of abstract logical thinking, so that teaching activities more in line with the natural thinking habits, so as to get better learning effect and higher learning efficiency.

3) Multimedia teaching make teaching image vivid: the use of multimedia teaching means, sound, image, character dynamic display, graphics and appearance, vivid, reached the abstract concept concrete, micro macro concept of good effect, to understand and accept [10]. Let students especially such as which witnessed, the experience, the mere rote rose in order to understand the application. The goal of the design of multimedia teaching is to help all the teachers make full use of information technology and information resources in their daily classroom teaching to cultivate students' information literacy, innovative spirit and problem solving skills, so as to enhance students' learning ability.

4) Two-way teaching information: If the teaching of multimedia and network technology into the teaching process, not only to achieve the communication between students and the computer, but also to achieve the communication between students and students, teachers and teachers. Teachers in total console can timely understanding of the specific circumstances of each student in computer operation, understand the student's thinking activity, mediation teaching process, the bidirectional communication function of dialogue among students, experience introduction and the instructor of student counseling, also can let the learning method when, learning good students to everybody introduce their experience, so as to improve the level of students' learning initiative and enthusiasm, truly teach students in accordance with their aptitude, making all the students can obtain satisfactory effect of learning.

\section{Research Object and Main Method}

\subsection{Time and Objects}

Study time from March 2015 to June 2015, a total of 16 weeks. Research object: 29 female students in martial arts routine options class of 2014 , from Guangxi University of Chinese Medicine. 


\subsection{Research Method}

The main research method including:

1) Literature method: through literature magazines, newspapers and books, Google Scholar, CNKI, the library and websites, newspapers, magazines and instant information retrieval, full access to domestic and foreign research literature review and carding, absorption and digestion of the achievements of the domestic and foreign martial arts and health related literature, understand the frontier and progress of the theoretical study of martial arts and health as much as possible, especially foreign scholars use the theory and method of, drawing on existing research results and research methods, the theoretical framework and hypotheses are proposed, and finding a useful reference for measurement of the empirical study of the concepts, for the results of the study provide security.

2) Test method: before and after the experiment of 29 students lung capacity, 50 meters, long jump, body anteflexion in sitting position were tested and record the results.

3) Questionnaire survey method: questionnaire survey is one of the important research methods, through the study of the structure of this paper empirically studies the measurement scale of the variables, and in the formal empirical study through the larger scale of the questionnaire survey to verify the research hypothesis and research hypothesis. The questionnaires were distributed in 32 copies, 30 copies, 29 valid questionnaires, the recovery rate was $93.75 \%$, the effective rate was $96.67 \%$. The validity of the questionnaire: on the basis of expert interview survey, statistical analysis and expert review, the content, structure and overall are effective, and can reflect the situation of the survey, which is in line with the needs of the study.

4) Comparative analysis: the comparison is the effective and the most commonly used method of thinking in human understanding, distinguishing and determining the relationship between things and differences.

5) Statistical methods: the use of $\mathrm{T}$ analysis, SPSS16.0 test, $\mathrm{P}>0.05$ is not statistically significant, $0.01<\mathrm{p}<0.05$ said there are significant differences between the two groups of data, $\mathrm{p}<0.01$ said there is a very significant difference between the two groups.

6) Logical reasoning: by using the method of comparison, deduction, induction, analysis and reasoning, the results of the statistical significance of the logical reasoning, the problem is more intuitive, specific, profound, from the corresponding theory.

\section{Empirical Analysis}

\subsection{The Impact on College Students' Body Function}

Vital capacity (VC) is one of the important indicators of physical function. It refers to a try to inhale, then try to breathe out the total amount of gas is a breath of maximal ventilator volume. Before and after the experiment, the indexes of male college students' body function (vital capacity) were measured, and the input SPSS16.0 statistical software was processed by Analyze to Means Compare to Means. Table 1 shows that the median and standard deviation of the test (3927.6 \pm 267.1$)$ after the experiment, and the standard deviation (3720.7 \pm 293.3 ), $206.9 \mathrm{ml}$ before the experiment, and $\mathrm{F}=7.890, \mathrm{P}=0.007<0.01$. The teaching of martial arts in ordinary colleges and universities can improve the vital capacity of college students. In ordinary university martial arts teaching, in the study and 
practice in itself is physical exercise, there is a large movement load and density, the process of active increase in breathing, slow suction fast call, slow suction when the chest slowly pull large, exhaled breath method and lead to a significant increase in lung capacity. Can be seen, the martial arts teaching in Colleges and universities will significantly improve the physical function of College students.

Table 1. The Influence of College Students' Physical Function

\begin{tabular}{|c|c|c|c|c|c|c|}
\hline Index & $\mathrm{N}$ & After exp. & Before exp. & difference & $\begin{array}{c}\mathrm{F} \\
\text { value }\end{array}$ & $\begin{array}{c}\mathrm{P} \\
\text { value }\end{array}$ \\
\hline $\begin{array}{c}\text { Vital capacity } \\
\text { (ML) }\end{array}$ & 29 & $\begin{array}{c}3927.6 \pm \\
267.1\end{array}$ & $\begin{array}{c}3720.7 \pm \\
293.3\end{array}$ & 206.9 & 7.890 & 0.007 \\
\hline
\end{tabular}

\subsection{The Impact on College Students' Physical Quality}

Body quality refers to the basic ability of human muscle, including speed, strength, endurance, agility and flexibility, etc. Include speed, strength, stamina, agility and flexibility and so on. Speed of representative projects of 50 meters, the power of representation of projects standing long jump, pliable representative projects to Sit and Reach. Table 2 shows that the median and standard deviation $(7.55 \pm 0.40)$ after the experiment, the median and standard deviation of the experiment $(8.01 \pm 0.54)$, after the experiment, $0.46 \mathrm{~s}$, and $\mathrm{F}=13.213, \mathrm{P}=0.001<0.01$. The median and standard deviation (229.93 \pm 12.44$)$ after the experiment were compared. The median and standard deviation were $9.48 \mathrm{~cm}$ and $\mathrm{F}=10.174, \mathrm{P}=0.002<0.01$. In "body anteflexion in sitting position index comparison, the median and standard deviation $(13.96+4.76)$, the mean and standard deviation (9.68 \pm 4.45$)$, after the experiment than before the experiment increased by 4.28 $\mathrm{cm}$ and $\mathrm{F}=12.484, \mathrm{P}=0.001<0.01$ That ordinary university martial arts teaching can improve the students very significant, 50 meters long jump and sit and reach. University Wushu teaching, the martial arts training and performing exercise intensity, time is short, the action line and curvature changes, reaction speed, the development of college students can better the movement speed and displacement speed, which was significantly increased in the 50 meter race; Wushu actions and basic action, there are a lot of strength exercise, such as jumping, single foot support, can enhance the leg muscle strength, improve jumping ability, which was significantly increased in the standing long jump; Wushu actions and basic action, need to own beautiful radian action action, action to drive radian muscle, tendons and ligaments stretch, thus making them soft tissue continue to enhance the extensibility and elasticity, which is very significant to improve the sitand reach. Can be seen, ordinary university martial arts teaching can be very significant to improve the physical quality of College students.

Table 2. The Influence of College Students' Physical Quality

\begin{tabular}{|c|c|c|c|c|c|c|}
\hline Index & $\mathrm{N}$ & After exp. & Before exp. & difference & F value & P value \\
\hline 50 metres (s) & 29 & $7.55 \pm 0.40$ & $8.01 \pm 0.54$ & -0.46 & 13.213 & 0.001 \\
\hline Long jump (cm) & 29 & $239.41 \pm 10.07$ & $229.93 \pm 12.44$ & 9.48 & 10.174 & 0.002 \\
\hline Sit and reach (cm) & 29 & $13.96 \pm 4.76$ & $9.68 \pm 4.45$ & 4.28 & 12.484 & 0.001 \\
\hline
\end{tabular}

\subsection{The Impact on College Students' Sports Hobbies}

Sports hobby is a kind of degree that people like sports. The questionnaire survey uses "satisfaction degree" as the investigation subject. Table 3 shows that the median and standard deviation (3.72 \pm 1.03$)$ after the experiment, the median and standard deviation of the experiment $(3.20 \pm 0.90)$, after the experiment, an increase of 0.52 points, and $\mathrm{F}=4.134, \mathrm{P}=0.047<0.05$. It is statistically significant before and after the experiment. In 
the teaching of Wushu in Colleges and universities, there are many sports games, martial arts competitions and Wushu spirit, which can improve the students' interest in learning martial arts. Can be seen, the martial arts teaching in Colleges and universities can significantly improve the degree of College Students' physical education.

Table 3.The Influence of College Students' Sports Hobbies

\begin{tabular}{|c|c|c|c|c|c|c|}
\hline Index & $\mathrm{N}$ & After exp. & Before exp. & difference & F value & P value \\
\hline sports hobbies & 29 & $3.72 \pm 1.03$ & $3.20 \pm 0.90$ & 0.52 & 4.134 & 0.047 \\
\hline
\end{tabular}

\subsection{The Impact on College Students' Sports Emotion}

Sports emotion is the emotion that people show in the course of sports, and it is very effective to cultivate and develop the students' physical training. The questionnaire survey was used to investigate the satisfaction degree of sports satisfaction. Table 4 shows that the median and standard deviation $(3.37 \pm 1.11)$ after the experiment, the median and standard deviation of the experiment (2.75 \pm 1.05$)$, after the experiment, an increase of 0.62 points, and $\mathrm{F}=4.730, \mathrm{P}=0.034<0.05$. It is statistically significant before and after the experiment. Wushu Teaching in Colleges and universities is an important part of our national traditional sports, with a long time, rich in content, profound cultural, complex and technical skills, sports load is moderate, teaching methods and means of diversification, college students physiological and psychological discomfort, and good and fast to promote physical and mental function, to achieve physical and mental pleasure. Can be seen, the martial arts teaching in Colleges and universities can significantly improve the emotional level of College students.

Table 4. The Influence of College Students' Sports Emotion

\begin{tabular}{|c|c|c|c|c|c|c|}
\hline Index & $\mathrm{N}$ & After exp. & Before exp. & difference & F value & P value \\
\hline sports emotion & 29 & $3.37 \pm 1.11$ & $2.75 \pm 1.05$ & 0.62 & 4.730 & 0.034 \\
\hline
\end{tabular}

\subsection{The Impact on College Students' Sports View}

Sports concept is people of physical understanding and judgment of the general views and the fundamental point of view, including the understanding of sports sports ideology, sports attitude, sports style, physical method and the success or failure of judgment and sports work standards. Table 5 shows that the median and standard deviation (4.20士 0.77 ) after the experiment, the median and standard deviation of the experiment (3. 31士 1. 00), after the experiment, an increase of 0.89 points, and $\mathrm{F}=14.515, \mathrm{P}=0.000<0.01$. It is statistically significant before and after the experiment. Because of the influence of our country elementary and middle schools "exam oriented education" and other factors, "valuing light weapons" misled the everyone's ideas, influence the students' sports view, "not important", "useless" sports concept restricts the development of students' comprehensive quality, through Wushu Teaching in Colleges and Universities, the essence of Wushu will significantly change students' sports attitude and thoughts, promote the formation of the concept of physical education and health. Can be seen, the martial arts teaching in Colleges and universities can be very significant to improve the degree of physical education of College students.

Table 5. The Influence of College Students' Sports View

\begin{tabular}{|c|c|c|c|c|c|c|}
\hline Index & $\mathrm{N}$ & After exp. & Before exp. & difference & F value & P value \\
\hline sports view & 29 & $4.20 \pm 0.77$ & $3.31 \pm 1.00$ & 0.89 & 14.515 & 0.000 \\
\hline
\end{tabular}




\subsection{The Impact on College Students' Sports Value Cognition}

Sports value refers to the sports meet the needs of human survival, development and enjoyment of the specific utility relationship is the relationship between the function of sports and human needs. According to the object of physical education can be divided into individual value and group value. According to the range of sports can be divided into physiological value, psychological value and social value. Table 6 shows that the median and standard deviation (3.96 \pm 0.94$)$ after the experiment, the median and standard deviation of the experiment (3.03 1.01$)$, before the experiment, an increase of 0.93 points, and $\mathrm{F}=13.051, \mathrm{P}=0.001<0.01$. It is statistically significant before and after the experiment. In China due to the influence of "college entrance examination baton" and other factors, physical teaching in middle school is not optimistic, resulting in serious students of inertial thinking and influence them to correct sports value views, they generally believe that physical education is an "optional", "there is no true value", the understanding is very paranoid and unscientific, through Wushu Teaching in Colleges and universities, Wushu culture and Wushu spirit of the individual value and the group value to obtain the full development, and promote the comprehensive development of College Students' physical value, psychological value and social value, promote the university students' sports value to raise awareness. Can be seen, the ordinary university martial arts teaching can be very significant to improve the students' Sports value.

Table 6. The Influence of College Students' Sports Value Cognition

\begin{tabular}{|c|c|c|c|c|c|c|}
\hline Index & $\mathrm{N}$ & After exp. & Before exp. & difference & F value & P value \\
\hline sports value cognition & 29 & $3.96 \pm 0.94$ & $3.03 \pm 1.01$ & 0.93 & 13.051 & 0.001 \\
\hline
\end{tabular}

\subsection{The Impact on College Students' Sports Motivation}

Sports motivation refers to the internal psychological factors causing and maintaining students' participation in physical training and physical training. It plays an important role in the sports activities, which is the function of orientation, adjustment, strengthening and maintenance. Table 7 shows that the median and standard deviation $(3.82 \pm 1.00)$ after the experiment, the median and standard deviation of the experiment $(3.13 \pm 0.87)$, after the experiment, an increase of 0.69 points, and $\mathrm{F}=7.789, \mathrm{P}=0.007<0.01$. It is statistically significant before and after the experiment. In the martial arts teaching in Colleges and universities, the interesting performance of the martial arts is quick to lead to the formation of students' direct motivation, and promote their sports motivation to develop in a good direction. Can be seen, the martial arts teaching in Colleges and universities can greatly improve the students' Sports motivation.

Table 7. The Influence of College Students' Sports Motivation

\begin{tabular}{|c|c|c|c|c|c|c|}
\hline Index & $\mathrm{N}$ & After exp. & Before exp. & difference & F value & P value \\
\hline sports motivation & 29 & $3.82 \pm 1.00$ & $3.13 \pm 0.87$ & 0.69 & 7.789 & 0.007 \\
\hline
\end{tabular}

\subsection{The Impact on College Students' Sports Will}

Sports will is the people in the sports activities in the conscious set goals, and to overcome all the difficulties, and ultimately achieve the goal of all mental activity. It can enhance the students to overcome difficulties, overcome the difficulties of confidence and perseverance, and promote the full development of College Students' physical and mental. Table 8 shows that the median and standard deviation (3.34 \pm 1.26$)$ after the experiment, the median and standard deviation of the experiment (2.58 \pm 1.15$)$, after the experiment, an increase of 0.76 points, and $\mathrm{F}=5.728, \mathrm{P}=0.020<0.05$. There are some difficulties in the 
teaching of Wushu routine in Colleges and universities, teachers should be gradual, and the students can overcome the difficulties, so that the sports will get better development. Can be seen, the martial arts teaching in Colleges and universities can improve the students' Sports will.

Table 8. The Influence of College Students' Sports Will

\begin{tabular}{|c|c|c|c|c|c|c|}
\hline Index & $\mathrm{N}$ & After exp. & Before exp. & difference & F value & P value \\
\hline sports will & 29 & $3.34 \pm 1.26$ & $2.58 \pm 1.15$ & 0.76 & 5.728 & 0.020 \\
\hline
\end{tabular}

\section{Conclusion}

Multimedia aided teaching is not only an important aspect of the reform of teaching, but also the driving force of the reform of teaching. It is a pioneering work. Teachers should suit the needs of society, make full use of the information technology, enrich the curriculum content, change the old teaching mode, and help students to form active learning attitude, and also help teachers to carry out creative teaching. New technology applied to teaching must be accompanied by new teaching ideas and methods, only to change the traditional teaching mode, combining the characteristics of new technology to create new teaching method and teaching mode, which can make the modern teaching technology fully and effectively applied in teaching and learning, realize the diversification, the main body and social.

The empirical results show that the martial arts teaching in Colleges and universities can greatly improve the physical function of college students. It can greatly improve students' physical education, sports value and sports motivation. It can improve students' physical education, sports and sports.

\section{Acknowledgments}

This work is financially supported by Jiangxi art scientific planning project (No. YG2011138).

\section{References}

[1] M. Sigala, "Investigating the role and impact of geovisualisation and geocollaborative portals on collaborative e-learning in tourism education", Journal of Hospitality, Leisure, Sport \& Tourism Education, vol. 11, (2012), pp. 50-66.

[2] C. Krstev and A. Trtovac, "Teaching Multimedia Documents to LIS Students", The Journal of Academic Librarianship, vol. 40, no. 2, (2014), pp. 152-162.

[3] W. Dai and L. Fan, "Discussion about the Pros and Cons and Recommendations for Multimedia Teaching in Local Vocational Schools", Physics Procedia, (2012).

[4] C. Zhang and X. Chen, "Use of Multimedia in Gross Infective Pathogen Experimental Teaching", Procedia Engineering, (2012).

[5] Y. Huang and S. Backman, "Experiencing student learning and tourism training in a 3D virtual world: An exploratory study", Journal of Hospitality, Leisure, Sport \& Tourism Education, vol. 13, (2013), pp. 190-201.

[6] H. Janta and P. Lugosi, "Migrant networks, language learning and tourism employment", Tourism Management, vol. 33, no. 2, (2012), pp. 431-439.

[7] S. J. Hua and L. Hong, "Explore the Effective Use of Multimedia Technology in College Physics Teaching”, Energy Procedia, (2012).

[8] M. Hu and S. Xu, "Research of Multimedia Teaching on Principles of Management", IERI Procedia, (2012).

[9] A. K. Kim and J. Davies, "A teacher's perspective on student centred learning: Towards the development of best practice in an undergraduate tourism course", Journal of Hospitality, Leisure, Sport \& Tourism Education, vol. 25, (2014), pp. 6-14.

[10] C. Wei and Y. Tao, "Application of Multimedia-Aided Project-Teaching Mode in Cultural Education", IERI Procedia, (2012). 